\title{
Lif Katkısının Beton Darbe Dayanımına Etkisi
}

\author{
Mehmet Hanifi Alkayış ${ }^{1 *}$, Celalettin Başyiğit ${ }^{2}$, \\ 1* Süleyman Demirel Üniversitesi, Mühendislik Fakültesi, İnşaat Mühendisliği Bölümü, Isparta, Türkiye, (ORCID: 0000-0003-0177-043X), \\ mehmethanifialkayis@gmail.com \\ ${ }^{2}$ Süleyman Demirel Üniversitesi, Mühendislik Fakültesi, İnşaat Mühendisliği Bölümü, Isparta, Türkiye, (ORCID: 0000-0003-0084-1320), \\ celalettinbasyigit@sdu.edu.tr
}

(2nd International Conference on Access to Recent Advances in Engineering and Digitalization (ARACONF)-10-12 March 2021)

(DOI: $10.31590 /$ ejosat.897865)

ATIF/REFERENCE: Alkayış, MH. \& Başyiğit, C. (2021). Lif Katkısının Beton Darbe Dayanımına Etkisi. Avrupa Bilim ve Teknoloji Dergisi, (24), 455-462.

$\ddot{\mathbf{O z}}$

Geçmişte gelişmiş savaş teknolojisinin olmayışı, cephenin gerisindeki tesisler ve yapıların güvende kalmasını sağlamaktaydı. Günümüzde ise ilerleyen savaş teknolojisi sonucu savaş anında cephedeki yapılar ile birlikte şehirlerdeki tesis ve yapılar da risk altında olmaktadır. Bu risklere karşı insan hayatını koruyan ve yaşamsal faaliyetlerin devamını sağlayan savunma yapıları inşa edilmektedir. Özellikle küresel olarak artan savaş riski savunma yapılarının önemini arttırmaktadır. Nükleer muhafazalar, köprüler, depolama yapıları ve askeri sığınaklar gibi stratejik ve önemli yapıların inşasında yaygın olarak kullanılan yapı malzemesi betondur. Betonun doğru bir şekilde tasarlanması ve imal edilmesi ile savunma ihtiyacı gereken yapılarda darbe, patlama ve dinamik etkilere karşı optimum fayda sağlanabilmektedir. Betonun darbe dayanımını agrega, su/ bağlayıcı oranı, minarel ve lif katkısı gibi beton bileşenleri etkilemektedir. Bu değişkenlerin etkileri sarkaç, ağırlık düşürme, bölünmüş Hopkinson basınç çubuğu ve sonlu elemanlar yöntemleri ile incelenmektedir. Bu çalışmada ise lif içeriği, türü ve incelik oranının beton darbe dayanımı üzerindeki etkisi araştırılmış ve değerlendirilmiştir.

Anahtar Kelimeler: Darbe Dayanımı, Lifli Beton, Lif Türleri

\section{Effect of Fiber Additive on Concrete Impact Strength}

\begin{abstract}
In the past, the lack of advanced warfare technology kept the facilities and structures behind the front safe. Today, as a result of the advancing war technology, the buildings on the front line and in the city are at risk during war. Defense structures that protect human life and ensure the continuation of vital activities are built against these risks. Especially, the global war risk increases the importance of defense structures. Concrete is the commonly used building material in the construction of strategic and important structures such as nuclear enclosures, bridges, storage structures and military bunkers. With the correct design and manufacture of concrete, optimum benefit can be achieved against impact, explosion and dynamic effects in structures that require defense. Concrete components such as aggregate, water / binder ratio, mineral and fiber additives affect concrete's impact strength. The effects of these variables are examined using pendulum, weight drop, split Hopkinson pressure bar and finite element methods. In this study, the effect of fiber content, type and fineness ratio on concrete impact strength was investigated and evaluated.
\end{abstract}

Keywords: İmpact Strength, Fiber Reinforcement Concrete, Fiber Types

\footnotetext{
* Sorumlu Yazar: mehmethanifialkayis@gmail.com
} 


\section{Giriş}

Savunma yapıları insan yaşamını korumayı amaçlayan, hisar, kale, sur, kule, istihkâmlar ve bu yapılarda bulanan birçok askeri yapılardır. Ancak ilerleyen savaş teknolojisi kale ve sur gibi eski savunma yapılarını korunmasız kılmıştır. 20. Yüzyıldan itibaren çelik ve beton gibi modern mühendislik tahkimatları yaygınlaşmaya başlamış ancak I. Dünya Savaşının getirdiği gelişmiş savaş teknolojileri bu tahkimatları da korunmasız kılmıştır. Günümüz de ise savaşlarda birçok farklı etkiye, ancak yerin altındaki sığınak türü yapıların tamamen koruma sağlayabileceği öngörülmektedir (Ekinci, 2019; Sığınak Yönetmeliği, 1998 ).

Dünyada askeri savunma yapılarının yanında, patlama, mermi veya füze çarpması, uçak kazası, düşme darbesi vb. gibi çarpma yüküne maruz kalma ihtimali olan birçok özel ve kamu yapıları mevcuttur. Betonlar, nükleer muhafazalar, köprüler, depolama yapıları ve askeri sığınaklar gibi stratejik ve önemli yapıların inşasında yaygın olarak kullanılan bir malzemedir. Betonun doğru bir şekilde tasarlanması ve imal edilmesi ile savunma ihtiyac1 gereken yapılarda optimum fayda sağlanabilmektedir(Feng vd., 2020; Rajput vd., 2018).

Doğal ve teknolojik tehlikelerden korunmak, barınma ve savunma ihtiyaçlarının karşılanmak için yapı malzemelerinin kullanımı ve gelişimi devam etmektedir. Yapı malzemesi olarak en çok kullanılan geleneksel beton, daha çok barınma ihtiyacı için kullanılmaktadır. Geleneksel beton çimento, iri agrega, ince agreganın ve suyun belirli karışım oranlarında homojen olarak karılması ile oluşan kompozit bir yapı malzemesidir. Ek olarak farklı amaç ve ihtiyaca göre üretilen özel betonlar da bulunmaktadır (Karslığlu ve Onur, 2020).

Özel betonlar, radyasyona karşı kullanılan ağır beton, kimyasal ve çevresel etkilere karşı geçirimliliği az beton, depreme karşı dayanıklılık için yüksek mukavemetli ve sünek betonlar vb. gibidir. Ayrıca bazı özel betonlar, inşaat ve savunma mühendisliği yapılarında, patlamalar ve yüksek hızlı darbeler gibi yoğun dinamik yüklere maruz kalabilen yapılarda yaygın olarak kullanılan bir malzemedir (Feng vd., 2020; Rajput vd., 2018).

Betonun kalitesi ve karakteristik dayanımı genel olarak beton basınç dayanımı deneyleri ile saptanmaktadır. Beton basınç dayanımı, beton elemanın kırılmadan karşılayabileceği maksimum gerilme değeridir. Betonun yüzeylerine farklı yönlerde yükler gelebilmekte ve bunu sonucu olarak basınç, çekme, eğilme ve kayma etkileri oluşabilmektedir. Bu etkiler yüksek olması sonucu betonda şekil değiştirme, çatlama ve göçme meydana gelebilmektedir. Beton tasarımı yapılırken, elemana gelecek bu etkiler göz önünde bulundurularak betonun gerekli mekanik özellikleri belirlenmektedir. Betonun mekanik özelliklerinin tasarımı ve analizi yapılan eleman dayanımını karşılaması gerekmektedir (Erdoğan., 2003).

Günümüzde artan insan ihtiyaçları ile birlikte inşaat sektöründe farklı amaçlarda kullanılmak üzere birçok farklı yapılar yapılmaktadır. $\mathrm{Bu}$ yapıların inşası için birçok yapı malzeme üretilmekte, özellikle en çok kullanılan yapı malzemesi olan betonun birçok mekanik özellikleri araştırılmaktadır. Betonun basınç, çekme, eğilme dayanımı vd. mekanik özellikleri birçok çalışma ile incelenmiş olup, bunların yanında betonun çatlama davranışı ve darbe dayanımı da araştırılmaktadır. Betonun mekanik parametrelerinden biri olan darbe dayanımını e-ISSN: 2148-2683 saptamak için uygulana etkinin türüne ve deneyin uygulanabilirliğine göre birçok metot geliştirilmiştir (Arıcı vd., 2007).

Bir yap1 veya yapı elemanı statik denge konumundan uzaklaştırılarak bırakıldığında bir titreşim hareketi yapar. Dış bir zorlama olmadığı takdirde bu hareket doğal titreşim hareketi ve bu hareketin kendini bir kez tekrarlaması için geçen süreye de doğal titreşim periyodu olarak tanımlanır. Eğer bir elemana doğal titreşim periyodunun üçte birinden daha kısa sürede bir etki olursa bu etki darbe olarak adlandirılmaktadır (Baradan, 2003). Darbe etkisi, çarpma, patlama, mermi ve bir elemanın düşmesi gibi şekilde olabilmektedir. Hava yolu pistleri, taşıt yolları, betonarme döşemeler, kazık ve istinat yapıları, askeri yapılar, savunma yapıları vb. birçok eleman darbe etkisinde kalabilmektedir. Bu etkide yapı elemanında gerilmeler ani olarak yükselir, malzemenin dayanıksız olması durumunda çatlak oluşumu ve ilerlemesi sonucu malzeme dayanımını yitirir ve göçer (Edgington, 1974). Yapı elemanında gerilmenin ani artışı malzemenin reolojisini araştırmayı zorlaştırmaktadır (Anık, 1999).

Bir elemanının darbe dayanımı, enerji yutma kapasitesi ve tokluk ile doğrudan ilişkilidir. Gerilme- birim şekil değiştirme grafiğinin altında kalan alanı ifade eden tokluğun yüksek olması için malzemenin sünek ve yüksek dayanıma sahip olması gerekmektedir (Anık, 1999). Normal tasarımda gevrek bir yapı malzemesi olan betonun, sünekliği ve yüksek dayanımı için birçok çalışma yapılmaktadır.

Malzemenin kırılma yüklemesi statik ve dinamik etkilerle olabilmektedir. Statik yüklemede malzemeye yükleme yavaşça yapılır ve gerilme- şekil değiştirme grafiğinden göçme davranışı incelenir. Dinamik yükleme de ise, malzeme darbe etkisine maruz birakılmaktadır. Darbe dayanımı deneyleri malzeme türüne göre değişmektedir. Metalik malzemelerde İzod veya Charpy çentik darbe deneyleri, yapı taşlarında ise genel olarak bir malzemenin düşürülmesi veya firlatılması deneyleri ile darbe dayanımı araştırılmaktadır (Anık, 1999).

Malzemenin darbe dayanımının incelenmesi için birçok yöntem bulunmaktadır. Bunlar;

- Hareketli Sarkaç - Charpy ve İzod Deneyleri

- Ağırlık Düşürme (yapı elemanı vd. cisimler)

- Bölünmüş Hopkinson Basınç Çubuğu Deneyi

- Mermi ve Patlayıcı Maddeler,

gibi yöntemlerdir.

Düşme ağırlığı ve sarkaç darbe testleri, nispeten düşük gerilme hızlarındaki etkiyi simüle etmek için yaygın olarak kullanılmaktadır. Malzemelerin yüksek gerilme hızları veya yüksek hızlı etkiler altındaki tepkisini incelemek için, normal olarak SHPB testi benimsenmektedir (Soufeiani vd., 2016).

Günümüzde, çelik lifli betonların dinamik davranışını araştırmak için birçok yöntem bulunmasına rağmen araştırmacılar tarafından tamamen kabul görmüş bir deney yöntemi mevcut değildir. Deney yöntemlerinin birçok değişkem malzeme ve deney sürecine bağlı olması bunda büyük etkendir. Ayrıca detaylı deneysel araştırmaların (mermi, TNT patlatma vs.) çok maliyetli olması dinamik davranış konusunda sayısal programları da gerekli kılmıştır. LS-DYNA, AUTODYN, ABAQUS vb. birçok numerik program yardımıyla lifli betonların statik ve dinamik davranışını araştırmak için etkili bir 456 
yöntem olmuştur. Son yıllarda birçok sayısal model önerilmiş, çok sayıda simülasyon ve analiz sunulmuştur. (Fang ve Zhang, 2013).

Terör saldırıları, kaza sonucu patlamalar ve tesadüfí etkiler nedeniyle dünya çapında çok sayıda yapının şu anda şiddetli darbelere ve patlayıcı yüklere direnmesi gerekmektedir. Bu tür dinamik yükler sırasında, oldukça yüksek gerilme oranları meydana gelmekte ve yapıya büyük miktarda enerji aktarılmaktadır (Soufeiani vd., 2016). Bu sebeple, bu çalışmada lifli betonların darbe dayanımı etki değişkenleri araştırılmıştır. Beton darbe dayanımı üzerinde büyük paya sahip olan lif katkısının etkisi üzerindeki çalışmalar ağırlıkla incelenmiştir.

\section{Beton Darbe Dayanımı Etki Değişkenleri ve Deneyleri}

Geleneksel betonun darbe dayanımı düşük olmasına rağmen kompozit bir malzeme olması, bu özelliğini geliştirebilme imkânı sağlamaktadır. Ancak betonun birçok bileşenin olması mekanik dayanımlarından biri olan darbe dayanımını da birçok yönden etkilemektedir. (Oltulu ve Altun, 2018). Görsel olarak beton darbe dayanımına etki eden değişkenler Şekil 2.1. verilmektedir.

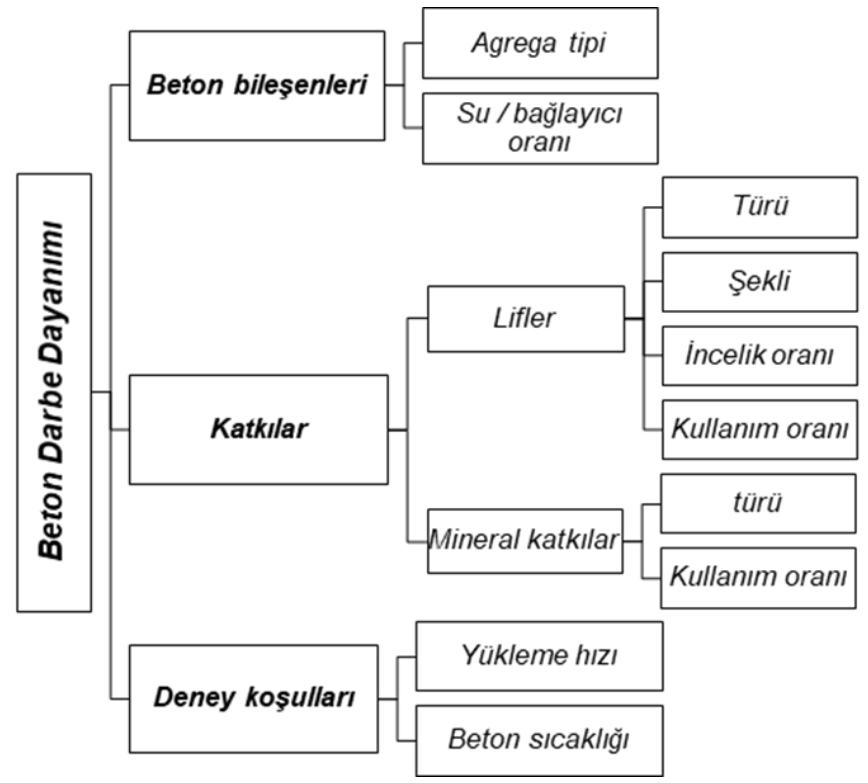

Şekil 2.1. Betonun darbe dayanımı etki değişkenleri (O, ğltulu ve Altun, 2018)

Beton bileşenleri, beton içerisindeki katkılar ve deney koşulları beton darbe dayanımını etkileyen ana unsurlardır. Beton bileşenlerini, agrega mineralojik ve fiziksel özellikleri, suçimento oranı oluşturmaktadır. Beton katkılarını, katkı çeşidi, kullanılan miktar, fiziksel ve mekanik özellikleri oluşturmaktadır. Deney koşullarını ise betonun sıcaklığı ve yükleme hızı oluşturmaktadır (Oltulu ve Altun, 2018).

Beton elemanların darbe dayanımını arttırmak için genellikle ana iki yaklaşım vardır. İlk yaklaşım, dayanımını arttırmak ve lif ekleyerek tokluğunu arttırarak beton özelliklerini geliştirmektir. İkinci yaklaşım ise betonun dışını koruyucu malzemelerle kaplamaktır. $\mathrm{Bu}$ malzemeler, darbe uygulayan cismin kinetik enerjisinin büyük bölümünü soğurabilen tampon bir kaplama görevindedir. Ayrıca, bunlar beton elemanın etrafını kapladığı için çatlama ve parçalanma sonucu oluşabilecek kalıntıları tutma yeteneği vardır (Aliabdo vd., 2013).
Beton darbe dayanımını arttırmak için bazı öneriler de şunlardır:

- Yüksek matris dayanımı

- Düşük çimento hamuru içeriği

- Betonda yüksek miktarda ince agrega içeriği

- Düşük boyutta maksimum agrega çapı ve tercihen kırmataş agrega kullanımı (Soufeiani vd., 2016).

Genellikle metalik malzemeler için kullanılan iki çeşit darbe deneyi vardır. Bunlar Charpy ve Izod çentik deneyleridir. İki deney yönteminde de ana ilke zayıflatılmış deney numunesinin bir pandül ile kırılmasıdır. Bu yöntemler arasındaki fark Charpy deneyinde numunenin yatay, Izod deneyinde ise dikey olarak mesnetlenmesidir. Şekil 2.1'de deney numunelerinin mesnetlenme durumları gösterilmektedir (Kocalmış, 2014).
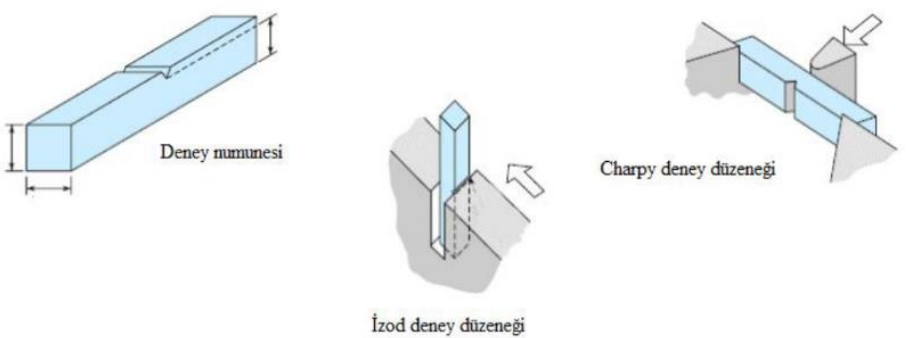

Şekil 2.2. Charpy ve İzod deney yöntemi numune konumlarl (Kocalmış, 2014)

Sarkaç darbe deneyleri, zayıflatılmış numunenin dinamik bir yük etkisinde kırılması için harcanan potansiyel enerjinin ölçülmesi ile gerçekleştirilir. Elde edilen değer malzemenin darbe dayanımını vermektedir (Arıcı vd., 2007).

Taş yapılı cisimlerin ve özellikle betonun darbe dayanımı için ekonomikliği ve kolay kullanımı sebebiyle çoğunlukla ağırlık düşürme deneyi kullanılmaktadır. $\mathrm{Bu}$ deneyler bir elemanın betona düşürülmesi şeklinde hem özel deney yöntemleri olabildiği gibi hem de standartlarca tanımlanmış yöntemlerde mevcuttur.

Amerika Beton Endüstrisi (ACI) 544.2R standardında ağırlık düşürme deneyi detaylandırılmıştır. Standarda göre bu deney, $4.45 \mathrm{~kg}$ ağırlığındaki yükün $457 \mathrm{~mm}$ yükseklikten $64 \times 150 \mathrm{~mm}$ boyutlarındaki disk numunenin üzerine yerleştirilen $64 \mathrm{~mm}$ çapında çelik bilye üzerine düşürülerek yapılmaktadır (bknz Şekil 2.3). Ayrıca deney sonuçları bağıntılar yardımıyla hesaplanmaktadır (Oltulu ve Altun, 2018).

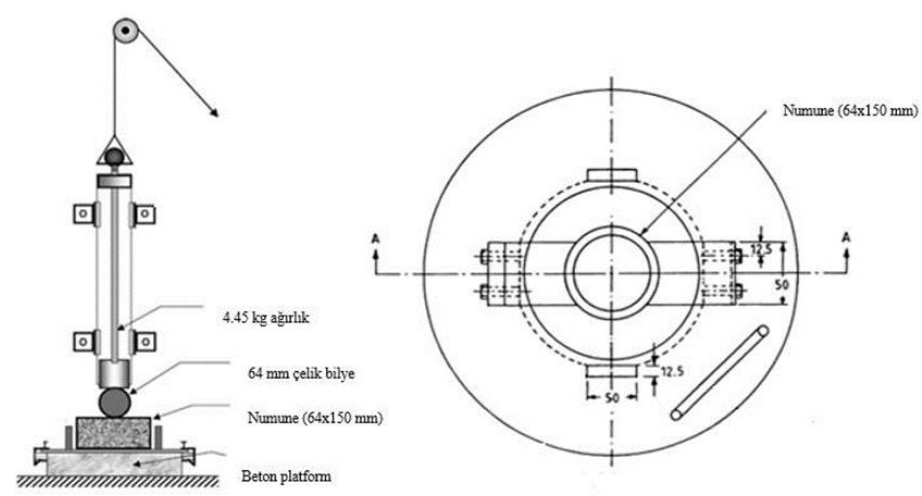

Şekil 2.3. Ağırlık düşürme deney cihazı (Arıcı, 2010) 
Betonun darbe dayanımını saptamak için gelişmiş yöntemlerden biri Şekil 2.4'de belirtilen yüksek hızda bölünmüş Hopkinson basınç çubuğu (SHPB) darbe deneyidir. Deney sistemi belirli bir hızda olan çubuğun çarptığı yüzeyde oluşturduğu deformasyonların belirlenmesi esasına dayanmaktadır (Xaio vd., 2015).

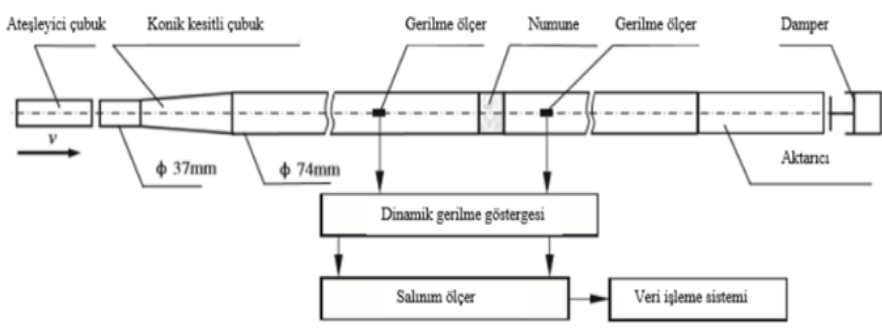

Şekil 2.4. $74 \mathrm{~mm}$ çaplı konik değişken kesitsel Bölünmüş Hopkinson Basınç Çubuğu (Xiao vd., 2015)

Patlama deney sistemi ise beton eleman üzerinde veya belirli bir mesafeye konulan patlayıcı malzemenin infilakı ile gerçekleştirilmektedir. Deney sonuçları gerinim ölçerler ve görsel ölçüm teknikleri ile takip edilmekte ve saysısal analizler yapılmaktadır. Deney sonucu hasar tespitinde çatlama, kırılma, göçme, bükülme vb. davranışlar betonun patlayıcı dinamik etkilere karşı dayanımı üzerine bilgiler vermektedir (Soufeiani vd., 2016).

Beton darbe dayanımı tespitinde sarkaç, ağırlık düşürme ve SHPB deneyleri kullanılarak birçok araştırma yapılmıştır. Bu araştırmalar sonucunda beton darbe dayanımını etkileyen Lif katkısının literatür araştırması alt bölümlerde yer almaktadır.

\subsection{Literatür Araştırması}

Betona lif katkısı basınç dayanımı üzerinde olumlu veya olumsuz sonuçlar oluşturabilmektedir. Ancak betonun sünekliği ve tokluğunu arttırdığı için darbe dayanımı arttırmada etkin parametredir. Liflerin darbe enerjisini sönümlemesi, ilk çatlak oluşumuna ve gelişimine karşı koyması darbe dayanımının artmasında en önemli nedenlerdendir. Beton içerisine çelik, polipropilen, cam, bazalt, poliamid, polivinil alkol, seramik, polietilen, naylon, kevlar ve doğal olmak üzere birçok türde lif eklenebilmektedir. En çok kullanılan lif türü çelik ve polipropilendir. Lif türüne ek olarak lif şekli, narinliği ve katkı oranı da beton darbe dayanımında önemli etkenlerdendir (Oltulu ve Altun, 2018).

Aliabdo vd. betonun darbe ve penetrasyon dayanımı üzerinde çelik liflerin etkisini incelemiştir. Deney serileri sonucunda düz, dalgalı ve kancalı uçlu (bknz. Şekil 2.2.) şekildeki çelik liflerin darbe dayanımında hafif bir etkiye sahip olduğuna varmışlardır. Kanca uçlu çelik lifli numunelerin, diğer çelik lif şekillerine ve sadece polipropilen lifli numunelere kıyasla önemli ölçüde daha iyi davranış göstermiştir. Ayrıca hacimce \% 0,1 ve $\% \quad 0,2$ polipropilen lif kullanımının, penetrasyon derinliği ve çatlak genişliği üzerinde, lifsiz beton numunelerine kıyasla önemsiz bir etkiye sahip olduğu gözlemlenmiştir. Ancak çelik lif kullanımının, lif içermeyen betona kıyasla penetrasyon derinliği ve çatlak genişliğini azaltıcı etkisi olduğu saptanmıştır. Lifsiz beton ile karşılaştırıldığında, $\% 1.0$ ve $\% 2.0$ düz çelik liflerin kullanılması sonucunda penetrasyon derinliği azalması sırasıyla yaklaşık \%16 ve \%22 olarak gözlemlenmiştir (Aliabdo vd., 2013).
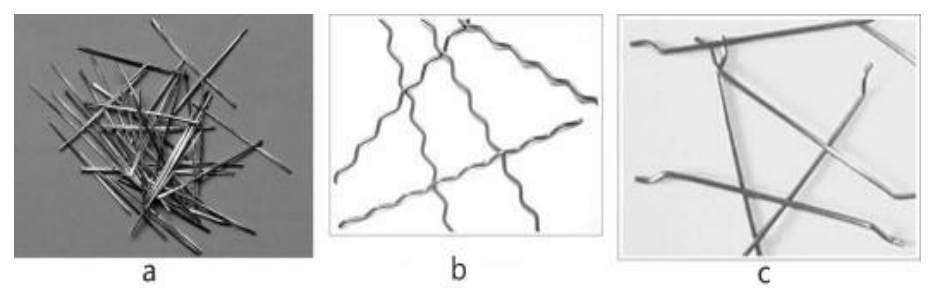

Şekil 2.5. çelik lif türleri; a)düz b)dalgalı c) kanca uçlu ( Aaliabdo vd., 2013)

Çelik lifli betonlar için ACI 544 standardına göre lif hacmi oranı $\%$ 0,5-1,5 arasında olmalıdır. Bu seviyenin aşılması betonun işlenebilirliği azaltır ve topaklaşmaya sebep olabilir. Ancak özel lif ekleme ve yerleştirme çalışmaları ile lif yüzdesi arttırılabilmektedir. Ayrıca basınç dayanımı 40 Mpa' dan fazla olan yüksek dayanımlı betonlarda da sünekliği arttırmak \%2 oranında kısa lifler kullanılabilmektedir. Yüksek dayanımlı lifli betonların sünekliğinin artması darbe dayanımını da arttırmaktadır. Basınç dayanımı çok yüksek (150-400 MPa) lifli betonlarda ise yüksek lif hacmi içeriği (\% 5-10) nedeniyle son derece sünek bir davranış göstermektedir. Bu özellik, elemanın kullanım ömrü sırasında büyük çatlaklar oluşturmadan donatıların etkin kullanımını sağlamaktadır (Soufeiani vd., 2016).

Çelik liflerin şekli açısından, spiral şekilli lifler ve kancalı uçlu lifler, darbe yükü altında diğer çelik lif türlerine göre daha iyi performans sergilemektedir. Kancalı uçlu çelik lifler, düşük hız etkisi altında çatlak genişliğini ve hasar mekanizmasını azaltmaktadır. Ayrıca tek tip lif içeriğinin yanısıra farklı tipte liflerin birleşiminden oluşan hibrit lifli betonlarda özellikle darbe dayanımına karşı önemli dayanım göstermektedir. Bu durumda farklı malzemelerden üretilen çeşitli şekil ve boyutlarda iki veya daha fazla lif, malzemeye her bir lifın yararlı özelliklerinden faydalanmak için eklenmektedir (Soufeiani vd., 2016).

$\mathrm{Xu}$ vd. kanca uçlu ve sipiral çelif lifli betonların statik ve dinamik mukavametlerini incelemiştir (bknz Şekil 2.6). Her iki türdeki lifli beton numunelerin çekme dayanımı, kırılma enerjisi, maksimum ölçülebilir birim şekil değiştimesi hem statik hem de dinamik deneylerde lifsiz betona göre daha iyi performans göstermiştir. Kancalı uçlu çelif lifli numuneler ise hem statik hem de dinamik koşullar altında sipiral lifli numunelere göre daha düşük gerilme mukavemeti ve kırılma enerjisi göstermiştir. Bunun nedeni, zayıf sürtünme kapasitesi ve kenetlenme bağının sadece kancaların yakınında olması olarak belirtilmiştir. Ayrıca sipiral çelik lif üç boyutta büklümlü yapısı sayesinde beton matrisi ile daha iyi bağlanması nedeniyle süneklik, tokluk, çatlak kontrol edilebilirliği açısından daha iyi performans göstermiştir (Xu vd.,2012).
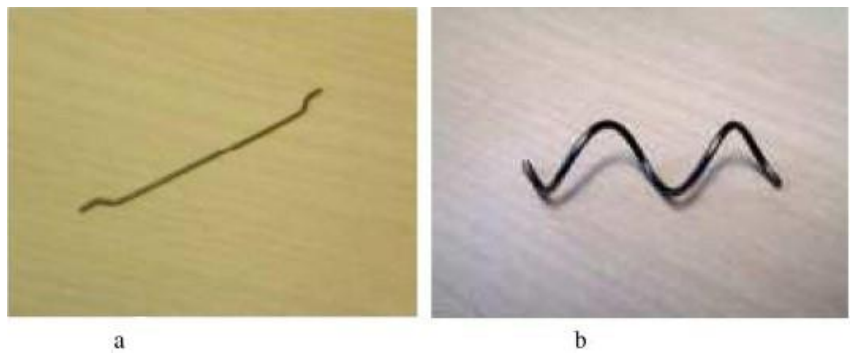

Şekil 2.6. Kanca uçlu (a) ve sipiral (b) çelik lif türleri( Xu., 2012) 
Xu vd. bir diğer çalışmada, farklı lif şekline sahip çelik lifli betonların dinamik basınç özelliklerini incelemek için düşme ağırlığı darbe deneyi gerçekleştirmiştir. Çalışmada farklı şekil ve malzeme özelliklerine sahip sentetik, dalgalı, soğuk haddelenmiş, yassılaştırılmış, kancalı uçlu ve bu çalışma için geliştirilmiş iki yeni spiral şekilli yedi lif türü ele alınmıştır (bknz Şekil 2.7). Tüm numunelerde sadece şeklin etkisini incelemek için hacimce \% 1 oranında lif kullanılmıştır. Ayrıcatüm numuneler için beton basınç dayanımı $35 \mathrm{MPa}$ olacak şekilde tasarlanmıştır. Lif şekillerinin betonun kırılma modları, mukavemeti ve enerji absorbe etme kapasitesi üzerindeki etkisi tartışılmıştır. Deney sonucunda bu çalışma için geliştirilen spiral çelik liferin (Şekil 2.7. g) beton matrisine daha iyi tutunma sağladığını ve dolayısıyla beton malzemeye daha iyi kenetlenme sağladığını, lifli betonun darbe dayanımını ve enerji yutma kapasitesini (tokluk) daha fazla arttırdığı göstermektedir (Xu vd., 2012).

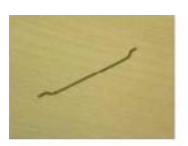

(a)

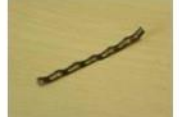

(b)

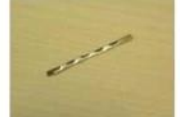

(c)

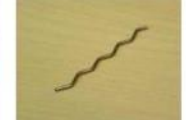

(d)

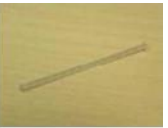

(e)

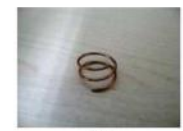

(f)

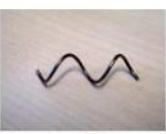

(g)
Şekil 2.7. Çeşitli şekillerdeki çelik lif türleri; a) kancalı uç, (b) düzleştirilmiş, (c) soğuk haddelenmiş, (d) dalgall, (e) sentetik, (f) spiral I ve (g) spiral II. ( Xu., 2012)

Grzymski vd. çalışmasında, betonun sünekliğini artırmak için geri dönüştürülmüş çelik liflerin (talaşlı imalat işleminden elde edilen) etkinliğini incelemiştir. Çelik lif ilavesinin etkisi, lifsiz, geri dönüşüm lifli ve kancalı uçlu çelik lifli olmak üzere 3 gurupta incelenmiştir (bknz Şekil 2.8). Bu seriler üzerinde basınç dayanımı, yarılma gerilme mukavemeti, eğilme mukavemeti ve eşdeğer eğilme mukavemeti gibi temel mekanik özellikler küp ve kiriş numunelerinde test edilmiştir. Betonu güçlendirmek için yaygın olarak kullanılan liflerin yerine geri dönüştürülmüş çelik liflerin potansiyel kullanımı araştırılmış ve tartışılmıştır (Grzymski vd., 2019).
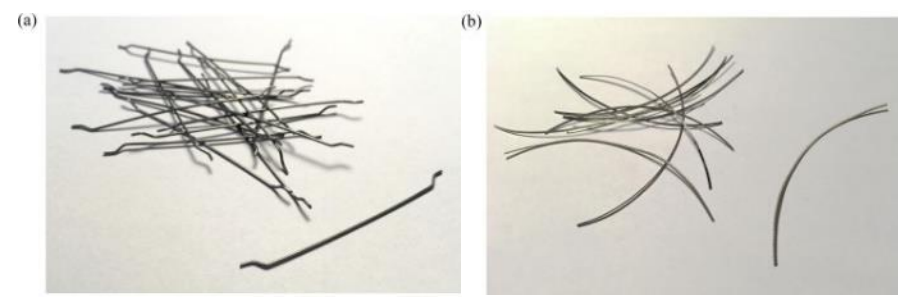

Şekil 2.8. Geri dönüştürülmüş (b) ve kancalı uçlu (a) çelik lif türleri(Grzymski vd., 2019).

Deney çalışması sonucunda geri dönüştürülmüş lifler kullanıldığında, kancalı uçlu çelik lifli betona göre enerji yutma kapasitesi yaklaşık altı kat daha düşük olduğu gözlemlenmiştir. Ayrıca geri dönüşüm lifler, mekanik özelliklerinde önemli ölçüde değişiklik göstermesinden dolayı kararlı bir beton matrisi elde edilemeyeceği vurgulanmıştır (Grzymski vd., 2019).

Mohammadi vd. farklı incelik oranına sahip çelik lifli betonun darbe dayanımını incelemiştir. $100 \times 100 \times 500 \mathrm{~mm}$ boyutlarında 108 normal ve lifli beton kiriş numunelerine darbe yükü uygulanmıştır. Deney serileri hacimce $1.0, \% \quad 1.5$ ve $\%$ oranında çelik lif içermektedir. Ayrıca lif boyunun 25 ve $50 \mathrm{~mm}$ olmasınında etkisi araştırılmıştır. Sonuçlar, \% 2,0 hacim oranında uzun lif ( $50 \mathrm{~mm}$ ) içeren betonun darbe yükü altında en iyi performansı verdiği görülmüştür (Mohammadi vd., 2009).

Kısa liflerin, çarpma yükünden kaynaklanan çatlakları durdurmada en az etkili oldukları vurgulanmaktadır. Bu durum küçük uzunlukları nedeniyle daha az bağlama direnci sunmaları ve matristen dișarı çekilmeleri nedeniyle olduğu ifade edilmektedir. Nihai kırılma anında darbe direncindeki artış, \% $1,0, \% 1,5$ ve \% 2,0 hacim kullanım oranına göre sırasıyla çelik lifli beton karışımları için \%968 ila \%943, \%1076 ila \%2428 ve\% 1337 ila\% 3211 arasında değișmiștir. Genel olarak, karıșık lif incelik oranlarında uzun lif yüzdesinin artması ve lif içeriğinin artmasıyla birlikte, ilk çatlakta ve nihai göçmede darbe direncinin arttığı elde edilmiştir (Mohammadi vd., 2009).

Zang vd. hibrit (bazalt-makro sentetik polipropilen) lifli betonun yüksek darbe yükleri altındaki darbe davranışını bölünmüş Hopkinson basınç çubuğu cihazı ile incelemiştir. Bazalt lifin (BL) içeriği hacimce $\% 0.05, \% 0.075$ ve $\% 0.1$ ve makro sentetik polipropilen lifin (PL) içeriği ise \% $0.15, \% 0.25, \% 0.35$ ve $\% 0.5$ arasında değişmektedir. Deney sonuçlarına göre, hem BL hem de PL betonun darbe dayanımını artırabildiği, BL numunesinin darbe dayanımının ve PL numunenini ise darbeye karşı dayanıklılığının daha yüksek olduğu gözlemlenmiştir. Ayrıca optimum hibrit lif karışımı, en iyi darbe direncine sahip olan \% 0,075 -\% 0,35 (BF-SF) numunesi olmuştur. Kullanılan lif türleri Şekil 2.9'da verilmiştir.

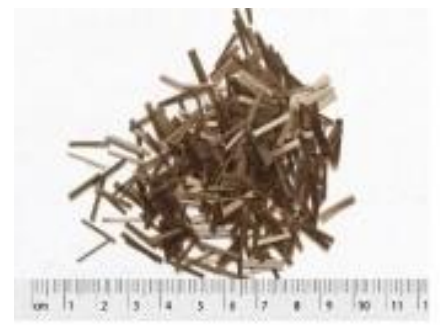

a

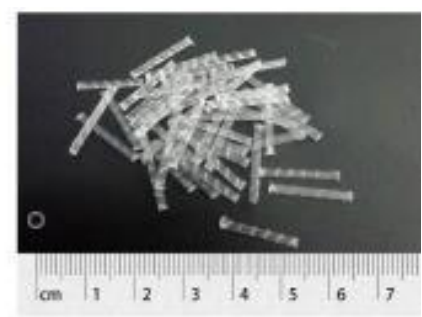

b
Şekil 2.9. Lif türleri; a) Bazlat lif, b) Polipropilen lif (Zang vd., 2019)

Darbe dayanımında betonda makro liflerin, mikro liflere göre daha faydalı sonuçlar vermektedir. Ayrıca makro ve mikro çelik liflerin uygun değerde birlikte eklemesi en etkili sonucu vereceği vurgulanmaktadır (Banthia vd., 1998).

Abid vd. çelik lifli kendiliğinden yerleşen betonun darbe dayanımını ACI 544-2R tarafindan önerilen tekrarlı darbe testini deneysel bir çalışma yapmıştır. Deneyde lif içeriğine ek olarak düşme ağırlığı ve düşme yüksekliğinin etkisini araştırılmıştır. Düz mikro çelik lifler, hacimsel olarak $0.5,0.75$ ve1 yüzdelerde normal betona ilave edilmiştir. Deney sistemi ise düșme yükseklikleri 450, 575 ve $700 \mathrm{~mm}$ ve ağırlıklar 4.5, 6.0 ve $7.5 \mathrm{~kg}$ olacak seçilde deneyler gerçekleştirilmiştir. Çalışma sonucunda mikro çelik lif ilavesi kendiliğinden yerleşen betonun darbe direncini, lif ilavesiz normal betona kiyasla \% 150 ila \%860 arasında değișen ölçüde artırdığı elde edilmiștir. Ayrıca 4,5 kg ağırlık $450 \mathrm{~mm}$ düşme yüksekliğinde test edilen numuneler darbe dayanımı gelişiminde en yüksek değeri göstermiştir (Abid vd., 2020).

Nili vd., polipropilen lif ve silis dumanı içeren beton karışımlarının darbe dayanımını incelemiştir. $12 \mathrm{~mm}$ uzunluğunda polipropilen lif hacimce $0,0.2,0.3$ ve 0,5 
yüzdelerde ve çimento ağırlığının \% 8'i oranında silis dumanı ikame edilmiştir. Çalışma sonucunda, polipropilen liflerin dâhil edilmesinin mekanik özellikleri iyileştirdiğini gözlemlenmiştir. Ayrıca silis dumanı ilavesi, liflerin dağılımını iyileştirdiği dolayısıyla betonun darbe dayanımını arttırmada etkili olduğu vurgulanmıştır. Özellikle silis dumanı ilavesi ile birlikte \%0,5 polipropilen lif kullanılması basınç, yarmada çekme, eğilme dayanımını ve betonun darbe dayanımını performansını $\operatorname{artırdığ1}$ ifade edilmiştir (Nili vd., 2010).

Arel vd. silis dumanı inceliğinin ve lif incelik oranının ultra yüksek performanslı lif katkılı betonun basınç ve darbe dayanımı üzerindeki etkisini deneysel olarak incelemiştir. $\mathrm{Bu}$ amaçla, beton numunelere farklı inceliğe $(17,200,20,000$ ve 27,600 $\left.\mathrm{cm}^{2} / \mathrm{gr}\right)$ sahip silis dumanı, çeşitli uzunluklarda $(8,13$ ve $16 \mathrm{~mm})$ lif ilave edilerek standart kür, buhar kürü ve sicak su kürüne tabi tutulmuştur. Basınç dayanımı deneyleri 7, 28, 56 ve 90. günde, darbe dayanımı deneyi ise 90 gülük kür süresinden sonra gerçekleştirilmiştir. Deney sonucunda $27.600 \mathrm{~cm}^{2} / \mathrm{gr}$ özgül yüzey alanlı silis dumanı ve $16 \mathrm{~mm}$ lif ilave edilen buhar kürüne tabi tutulan numunenin mekanik özellikler açısından diğer karışımlara göre daha iyi sonuçlar verdiği elde edilmiştir. Ayrıca lif incelik oranı artması ile darbe dayanımı arttığ gözlemlenmiştir (Arel vd., 2016).

Lee vd. amorf metal lif uzunluklarının, çimento esaslı kompozitlerin eğilme ve çekme özellikleri ile darbe dayanımına olan etkilerini incelemiştir. Numuneler hacimce \% 1.0 veya $\% 2.0$ amorf metalik liflerin (15 veya $30 \mathrm{~mm}$ uzunluklardaki) eklenmesi ile imal edilmiştir. Statik eğilme ve çekme testlerinden sonra, $25 \mathrm{~mm}$ çaplı küresel bir mermi ile yüksek hızlı (170 ve $300 \mathrm{~m} / \mathrm{s})$ darbe deneyi yapılmıştır. $30 \mathrm{~mm}$ uzunluğundaki amorf metalik lifler, çekilmeden kırılıncaya kadar gerilmenin emilmesi ve dağılımına bağlı olarak kırılmaların yayılmasını absorbe etmil, bu da çimento esaslı kompozitlerin eğilme ve gerilme özelliklerini önemli ölçüde arttırmıştır. $15 \mathrm{~mm}$ lifler $30 \mathrm{~mm}$ 'ye kıyasla eğilme ve gerilme özelliklerinde ve darbe direncinde daha küçük sonuçlar vermiştir.(Lee vd., 2021).

Kızılırmak vd. çok kancalı (4D ve 5D) liflerin kullanım oranı ve incelik oranının yüksek dayanımlı betonların statik ve darbe dayanımını üzerine etkisini araştırmıştır (bknz Şekil 2.6). Deney serilerinde 3D tipi çelik lifli numuneler referans olarak alınmıştır. Çalışma sonucunda en iyi performansı 5D 65/60 (incelik oranı 65 ve boyu $60 \mathrm{~mm}$ ) çelik lif göstermiştir. Ayrıca çelik liflerdeki kanca sayısının artması ile numunenin eğilme mukavemeti ile kırılma enerjisinde artış gözlemlenmiştir. Ek olarak 4D lif türünün incelik oranının artması ile birlikte numunelerin mekanik özelliklerinde değişimler başlamıştır. Ayrıca 3D lif türünde kırılma enerjisi incelik oranının artması ile azalmıştır. Darbe dayanımında ise en iyi performans, 4D 65/60 ve 5D 65/60 lif türünde gözlemlenmiştir (Kızılırmak vd., 2019).
$3 \mathrm{D} 65 / 60$

$4 \mathrm{D} 65 / 60$

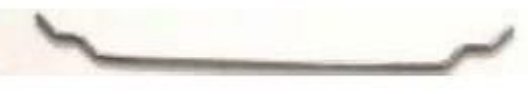

$5 \mathrm{D} 65 / 60$

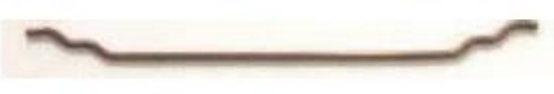

$3 \mathrm{D} 80 / 60$

\section{$4 \mathrm{D} 80 / 60$}

Şekil 2.10. Farklı şekil (3D, 4D ve 5D) ve incelik oranına göre lif türleri (Kızılırmak vd., 2019)

Fang ve Zhang, darbe ve patlama yüklemesi altında çelik lifli beton malzemenin dinamik tepki ve hasarını incelemek için bir üç boyutlu sayısal model sunmaktadır. 3D sayısal modelde numunenin daha düşük mukavemetli homojen beton matrisinden ve daha yüksek mukavemetli çelik liflerden oluştuğu varsayılmaktadır (bknz Şekil 2.11). Düz yuvarlak çelik liflerin matriste rastgele konumlar ve yönelimlerle dağıldığ varsayılmakta ve sonlu eleman analiz modelini oluşturmak için bir üç boyutlu (3D) ağ algoritması tanıtılmıştır. Lif ve matris arasındaki etkileşim, bağlanma ve kayma temas algoritması ile modellenmiştir. Lifli betonun mekanik davranışı simüle edilmiş ve deney verileriyle iyi bir uyum gözlemlenmiştir. Temasl patlama altındaki lifli beton numuneler için geliştirilen sayısal modelin hasar modunu kesin olarak tahmin edebileceğini görülmüştür (Fang and Zhang, 2013).

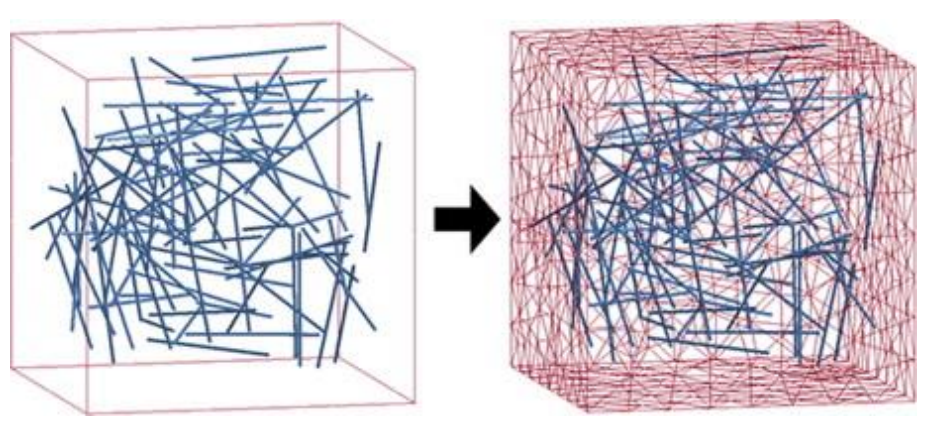

Şekil 2.11. 3D Sonlu eleman analizi modeli (Fang ve Zhang, 2013)

Badr. vd. polipropilen lifli betonun darbe direncini, ACI-544 standardında önerilen tekrarlanan düşme ağırlığı darbe deneyini istatistiksel olarak analiz etmiştir. Deney sonuç varyasyonları aynı parti seri içerisinde ve farklı seriler arasında incelenmiştir. Ayrıca istatistiksel parametreler, karbon ve çelik lifler gibi diğer beton kompozitlerin darbe direncinde bildirilen değişimlerle karşılaştırılmıştır. İstatistiksel analiz, Polipropilen lifli betonun darbe deneyinden elde edilen sonuçlar büyük farklılıklar göstermiştir. \% 10'un altında bir hatanın altına inmek için beton karışımı başına en az 40 numunenin incelenmesi gerektiği sonucu elde edilmiştir. Mevcut prosedürleri ve önerileri ile bu testin güvenilir bir darbe testi olarak değerlendirilmemesi gerektiği sonucuna varılmıştır (Badr vd., 2006). 


\section{Araştırma Sonuçları ve Tartışma}

İncelenen çalışmalar sonucu dareb dayanımına; basınç dayanımı, eğilme mukavemeti, lif içeriği ve lif özellikleri (uzunluk, en-boy oranı, lif tipi) özelliklerinin değişmesi sebep olmaktadir.

Betonun darbe dayanımını etkileyen parametreler arasında olan lif katkısı en etkili olduğu ve lif içeriğinin kontrollü bir şekilde arttırılmasının darbe dayanımını arttırdığına varılmıştır. Özellikle tek çeşit lif kullanımında çelik liflerin diğer tek çeşit kullanılan liflere göre en iyi performans gösterdiği belirtilmektedir. Ancak maliyetin düşürülmesi, atık azaltımı ve betonun diğer özelliklerin geliştirilmesi açısından hibrit (karma) lifli beton kullanımı darbe dayanımı açısından faydalı sonuçlar verecektir.

Betona birçok dinamik yük etkiyebilmektedir. Bu yüzden beton darbe dayanım deneyleri farklı olmaktadır. Bu yöntemlerin birbirlerinden faklı süreçler olması darbe dayanımı konusunda çalışmaların daha da araştırılmasına yol açmaktadır. Ancak tamamen kabul görmüş bir standardın olmayışı sebebiyle numunenin maruz kalacağı dinamik etkiye göre deney sistemi seçilmelidir. Numune davranışının deney sistemine göre değişebildiği göz önünde bulundurulmalıdır.

Darbe dayanımı ölçüm yöntemlerinden en kolay uygulanan ve en ekonomik olan ağırlık düşürme deneyi en yaygın olandır. Ancak istatistiksek olarak deney serilerinde standart sapmanın yüksek olması deney sisteminin güvenirliğini sorgulatmaktadır.

Betona lif eklenmesi beton sünekliği ve tokluğunu arttırması sebebiyle darbe dayanımında da artışa sebep olmaktadır. Lif eklenmesinin yanı sira beton dayanımının artması da darbe dayanımını arttırmaktadır. $\mathrm{Bu}$ sebeple beton dayanımını etkileyen tüm parametreler darbe dayanımını da etkilemektedir.

Çelik lif kullanımının şekilden bağımsız olarak betonun sünekliğini, enerji yutma kapasitesini ve darbe dayanımını attırdığı açıktır. Ayrıca betonun darbe dayanımını arttırmada çelik lif şeklinin kenetlenme kapasitesinin artması oranında etkili olmaktadır. Özellikle yeni lif şekillerinin betonun darbe dayanımını arttırmada önemli rol oynayabileceği öngörülmektedir.

Genel olarak lif boyunun artması ve lif kullanım oranının lif türüne göre değişmek te beraber çelik liflerde $\% 1$ ve $\% 2$ arasında kullanılmasııın en iyi performası vereceği görülmektedir. Ayrıca incelik oranının artması da darbe dayanımını arttıran etkenlerdendir. Ek olarak farklı lif şeklinin geliştirilmesi hem çelik hemde diğer lif türlerinde darbe dayanımını etkileyecektir.

\section{Sonuç}

$\mathrm{Bu}$ çalışma, betonların darbe dayanımında lif türü, şekli, kullanım oranı ve incelik oranının etkileri üzerine deneysel araştırmaların incelemesi sunulmuştur.

Yapılan çalışmalar çoğunlukla çelik liklerin kullanım hacim oranını kontrollü olarak artırmanın darbe direnci ve mekanik özellikleri artırdığı göstermiştir. Ayrıca, beton karışımına daha iyi kenetlenme etkisi sebebiyle çelik lifler için en uygun şekillerin spiral ve kancalı uçtur. Ek olarak lif uzunluğunun artması da darbe dayanımında artışa sebep olmaktadır.
Darbe dayanımı birçok deney yöntemi ile belirlenebilmektedir. En uygun yaklaşım elamanın maruz kalacağı dinamik yüke göre seçilmelidir. Deney koşulları, elemanın türü vs. parametreler deney seçiminde oldukça etkilidir. Ayrıca deneysel yöntemlerin sayısal simülasyonlar ile karşılaştırılması da betonun darbe davranışı üzerine elde edilecek sonuçların değerlendirilmesinde bir araçtır.

Sonuç olarak, darbe dayanımı deneyi basit yapı malzemeleri üzerinde denenmektedir. $\mathrm{Bu}$ sebeple büyük ölçekli yapı elamanlarında tasarım için tamamen güvenli deney sistemi olmadığı açıktır. Birçok darbe dayanımı etki değişkeninin olması da bu deneylerin tek başına etkili tasarım yöntemi olmayacağını göstermektedir. Ek olarak, gelişmiş deney sistemlerinin maliyetleri de araştırmaları engellemektedir. Bu sebeple sayısal analiz yöntemleri geliştirilmeye devam edilmektedir.

\section{Teşekkür}

Bu çalışma, YÖK 100/2000 doktora projesi 'Yapı, Yapı Malzemesi ve Yapı Yönetimi' öncelikli alan vizyonu göz önünde bulundurularak gerçekleştirilmiş̧ir. Verilen desteklerinden dolayı ilgili YÖK ve YÖK 100/2000 personeline teşekkür ederiz.

\section{Kaynakça}

Sığınak Yönetmeliği (1988) 25.08.1988 tarih ve 19910 Sayılı Resmi Gazete.

Abid, S. R., Abdul-Hussein, M. L., Ayoob, N. S., Ali, S. H., \& Kadhum, A. L. (2020). Repeated drop-weight impact tests on self-compacting concrete reinforced with micro-steel fiber. Heliyon, 6(1), e03198.

Aliabdo, A. A., Abd_Elmoaty, A. M., \& Hamdy, M. (2013). Effect Of İnternal Short Fibers, Steel Reinforcement, And Surface Layer On İmpact And Penetration Resistance Of Concrete. Alexandria Engineering Journal, 52(3), 407-417.

Anık, S., Metalik Malzemelerin Mekanik Deneyleri, Birsen Yayin Evi, İstanbul, 1999.

Arel, H. Ş. (2016). Effects of curing type, silica fume fineness, and fiber length on the mechanical properties and impact resistance of UHPFRC. Results in physics, 6, 664-674.

Arıc1, E., Dursun, R., \& İnce, R. Betonun Çarpma Mukavemetinin Tesbiti.

Badr, A., Ashour, A. F., \& Platten, A. K. (2006). Statistical variations in impact resistance of polypropylene fibrereinforced concrete. International Journal of Impact Engineering, 32(11), 1907-1920.

Banthia, N., Yan, C., \& Sakai, K. (1998). Impact Resistance Of Fiber Reinforced Concrete At Subnorma Temperatures. Cement And Concrete Composites, 20(5), 393-404.

Baradan, B. (2003). İnşaat Mühendisleri İçin Malzeme Bilgisi. İzmir De Ü. Müh. Fak. Yayın, (307), 394.

Edgington, J., Hannant, D. J. And Willıams, G. I. T., "Steel Fibre Reinforced Concrete", Building Research Establishment Current Paper, Cp 69/74, July 1974.

Ekinci, C. E. (2019). Savunma Ve Sığınma Yapılarında Kbrn Tehditlerine Karşı Betonların Zırhlanması. Engineering Sciences, 14(3), 119-153. 
Erdoğan, T. Y., Beton, Odtü Geliştirme Vakfı Yayıncı Ik Ve İletişim A.Ş., Ankara, Mayıs 2003. 3. Esen, Y., "Poliakrilonitril Lif Takviyeli Betonların Mekaniksel Özelliklerinin Ve Kullanılabilirliğinin Araştı Ilması”, F.Ü. Fen Ve Mühendislik Bilimleri Dergisi, Vol. 15, Pp.47-54, Elazığ, 2003.

Fang, Q., \& Zhang, J. (2013). Three-Dimensional Modelling Of Steel Fiber Reinforced Concrete Material Under İntense Dynamic Loading. Construction And Building Materials, 44, 118-132.

Feng, J., Sun, W., Wang, L., Chen, L., Xue, S., \& Li, W. (2020). Terminal Ballistic And Static İmpactive Loading On Thick Concrete Target. Construction And Building Materials, 251, 118899.

Grzymski, F., Musiał, M., \& Trapko, T. (2019). Mechanical properties of fibre reinforced concrete with recycled fibres. Construction and Building Materials, 198, 323-331.

Karslıoglu, A , Onur, M . (2020). Uzayda Yerli Kaynaklar ile Yap1 Malzemesi Üretimi . Avrupa Bilim ve Teknoloji Dergisi , Ejosat Özel Sayı 2020 (ARACONF), 216-223 . DOI: 10.31590/ejosat.araconf27

Kızılırmak, C., Aydın, S., \& Yardımcı, M. Y. (2019). Çelik Lif Kanca Geometrisinin Yüksek Dayanımlı Lifli Betonların Statik Ve Darbe Yükleri Altında Eğilme Özelliklerine Etkisi. Journal Of The Faculty Of Engineering \& Architecture Of Gazi University, 34(3).

Kocalmış, Z. (2014). İzod Metodunda Beton Numune Boyutunun Çarpma Dayanımına Etkisi/Effect Of İmpact Strength Of Concrete Sample Size İn İzod Method.

Lee, S., Kim, G., Kim, H., Son, M., Choe, G., Kobayashi, K., \& Nam, J. (2021). Impact resistance, flexural and tensile properties of amorphous metallic fiber-reinforced cementitious composites according to fiber length. Construction and Building Materials, 271, 121872.
Mohammadi, Y., Carkon-Azad, R., Singh, S. P., \& Kaushik, S. K. (2009). Impact resistance of steel fibrous concrete containing fibres of mixed aspect ratio. Construction and Building Materials, 23(1), 183-189.

Nili, M., \& Afroughsabet, V. (2010). The effects of silica fume and polypropylene fibers on the impact resistance and mechanical properties of concrete. Construction and Building Materials, 24(6), 927-933.

Oltulu, M., \& Altun, M. G. Betonun Darbe Dayanımının Tespitinde Ağırlık Düşürme Deney Yöntemi Ve Yapılan Çalışmalar. Gümüşhane Üniversitesi Fen Bilimleri Enstitüsü Dergisi, 8(1), 155-163.

Rajput, A., Iqbal, M. A., \& Gupta, N. K. (2018). Ballistic Performances Of Concrete Targets Subjected To Long Projectile İmpact. Thin-Walled Structures, 126, 171-181.

Soufeiani, L., Raman, S. N., Jumaat, M. Z. B., Alengaram, U. J., Ghadyani, G., \& Mendis, P. (2016). Influences Of The Volume Fraction And Shape Of Steel Fibers On FiberReinforced Concrete Subjected To Dynamic Loading-A Review. Engineering Structures, 124, 405-417.

Xiao, J., Li, L., Shen, L., \& Poon, C. S. (2015). Compressive Behaviour Of Recycled Aggregate Concrete Under İmpact Loading. Cement And Concrete Research, 71, 46-55.

Xu, Z., Hao, H., \& Li, H. N. (2012). Dynamic tensile behaviour of fibre reinforced concrete with spiral fibres. Materials \& Design, 42, 72-88.

Xu, Z., Hao, H., \& Li, H. N. (2012). Experimental study of dynamic compressive properties of fibre reinforced concrete material with different fibres. Materials \& Design, 33, 4255.

Zhang, H., Wang, L., Bai, L., Addae, M., \& Neupane, A. (2019). Research on the impact response and model of hybrid basalt-macro synthetic polypropylene fiber reinforced concrete. Construction and Building Materials, 204, 303316. 